\title{
RECONCILING CONSUMER CONFIDENCE AND PERMANENT INCOME CONSUMPTION
}

\author{
K. H. McIntyre \\ McDaniel College
}

\section{INTRODUCTION AND OVERVIEW}

Consumer confidence and its macroeconomic impact is a topic receiving increasing attention from economists, policymakers, journalists, and financial analysts alike. The basic notion is that consumer confidence, measured using indexes created from household surveys, is an important determinant of not only present, but also future household consumption expenditures. Given the vital role consumption plays in overall macroeconomic performance-it is a stylized fact that consumption accounts for roughly two-thirds of GDP in the U.S. and other developed countries-understanding the relationship between consumer confidence and current and future consumption expenditures is an issue of great interest to forecasters, policymakers, financial markets, and the business community.

On a cursory level, the evidence supporting the link between consumer confidence and consumption is quite compelling: household consumption has tended to slow following a dip in consumer confidence and vice versa for decades [Abderrezak, 1997]. Evidence also exists on a not-so-cursory level. A study by Bram and Ludvigson [1998] suggests that, depending on the confidence measure used, consumer confidence has significant predictive power for growth in consumption spending. Danthine et al. [1998] take this a step further, linking consumer confidence to expectations concerning longterm labor productivity growth and hence permanent income. Likewise, Matsusaka and Sbordone [1995] have shown that consumer confidence accounts for approximately $20 \%$ of the business cycle innovation in postwar U.S. GDP. Thus, consumer sentiment, through patterns of consumption spending, affects not only the intensity of business cycles, but also their duration.

As consumer confidence is a possible measure of forward-looking behavior on the part of households, it is important to understand its relationship with life-cycle/ permanent income models of consumption. In many ways, consumer confidence fits naturally with the permanent income hypothesis (PIH). As a coincident indicator, it is highly correlated with the present state of the economy and thus reflects both current and near-term income prospects. Consumer confidence is also influenced by forward-looking variables such as equity prices and interest rates, and may thus be capturing information regarding expectations of future income prospects.

In the strictest sense, however, consumer confidence, or better its predictive power, is not consistent with the PIH. Under standard versions of the PIH, consumer sentiment and other macroeconomic indicators (current income, inflation and unemploy-

$\overline{\text { K. H. McIntyre: Department of Economics and Business Administration, M}}$ cDaniel College, 2 College Hill, Westminster, MD 21157. E-mail: mcintyre@mcdaniel.edu.

Eastern Economic Journal, Vol. 33, No. 2, Spring 2007 
ment rates, etc.), should have no predictive power for consumption growth beyond their capacity to signal changes in permanent income [Flavin, 1981]. This may not be the case empirically, however; there is evidence to suggest that consumer confidence by itself contains something useful for explanatory and/or predictive purposes beyond what can be gleaned from the fundamentals [Carroll et al., 1994; Bram and Ludvigson].

This paper reconciles the predictive power of consumer sentiment with the PIH by developing a "confidence augmented" permanent income model that features consumer confidence as part of the household preference specification. In this framework, the predictive power of consumer confidence is consistent with the $\mathrm{PIH}$, and empirical results suggest that including consumer confidence in this way does not significantly alter the predictions of standard PIH models concerning the degree of permanent income spending undertaken by households. In contrast, including consumer confidence has significant implications for intertemporal substitution: adding consumer confidence substantially decreases estimates of the intertemporal elasticity of substitution.

The remainder of the paper is organized as follows: one section describes the data and presents preliminary empirical evidence; the next section describes the relationship between consumer confidence and the permanent income/life-cycle model of consumption; the next section develops the confidence-augmented model; the next section describes estimation procedures and reports baseline results; the section investigates the robustness of the confidence-augmented PIH model; the next section concludes.

\section{PRELIMINARY EMPIRICAL EVIDENCE}

\section{Data Description}

Two measures of consumer confidence are considered: the Conference Board's Consumer Confidence Index (CCI) and the University of Michigan Index of Consumer Sentiment (ICS). Each index features an expectations component which is also examined. These indexes are the most closely watched measures of consumer attitudes in the U.S., and a detailed discussion of their respective properties is found in the proceeding subsection. Household spending is defined formally as consumption of non-durable goods and services. Income is measured using gross personal income. Consumption and income data are obtained from the Bureau of Economic Analysis' National Income and Products Accounts; both indicators are chain-weighted and expressed in per-capita terms. A variety of interest rates and asset returns are considered. The primary interest rates are the yield on 3-month commercial paper, the 3 -month Treasury yield, and the 90 -day CD rate. Stock returns are measured using quarterly changes in the Standard \& Poor's 500 index. The return to tangible assets is proxied by the growth rate in house prices calculated from the National Association of Realtors' median house price series. Nominal interest rates and asset returns are converted to ex-post real rates using 4-quarter changes in the Consumer Price Index. Finally, the sample period is 1978:Q1-1998:Q4, the former date corresponding to the first release of the Conference Board index on a monthly frequency. 


\section{Statistical Properties}

Although the Conference Board and University of Michigan indexes are designed to capture individuals' attitudes regarding the current and perceived near-term performance of the U.S. economy, they are not homogenous. While both are constructed from household surveys, they differ in sample size, the questions that are asked, the mechanical construction of the index, and the way each survey is scaled. ${ }^{1}$ Not surprisingly, the statistical properties of each index and its expectations component differ substantially. As illustrated in Table 1a, the four measures of consumer confidence exhibit dramatically different volatilities. With standard deviations of .0234 (log levels, Hodrick-Prescott filtered) and .0386 (log differences), the smoothest series is the expectations component of the University of Michigan index. The broad Michigan index is twice as volatile as its expectations component. Finally, the Conference Board series are considerably more volatile than their Michigan counterparts. The broad Conference Board index, for example, is six times as volatile as the Michigan index in levels and twice as volatile in growth rates. The Conference Board expectations series is less volatile than the broad index, but its standard deviation is four times that of the Michigan expectations index in both levels and growth rates. ${ }^{2}$

Consumer confidence is highly volatile relative to both consumption and income. Indeed, the level standard deviation of consumer confidence ranges from approximately three (Michigan expectations) to 50 times (Conference Board) that of consumption, and from roughly twice to 35 times that of personal income. A similar pattern is observed with growth rate correlations. Depending on which measure is considered, changes in consumer confidence are between 10-40 times as volatile as consumption growth, and 5-20 times as volatile as income growth.

In addition, both indexes exhibit different behavior over the course of the business cycle. As noted by Bram and Ludvigson [1998], the Michigan index typically crests early in an expansion period while the Conference Board index does so in the middle or towards the end. This difference can be seen in the fact that the various measures of consumer confidence are positively correlated with one another, although not as strongly as one might expect (see Table 1b). The two broad indexes, for example, share $a+0.61$ correlation in levels and a +0.49 correlation in growth rates. The correlations for the expectations series are stronger, at +0.79 in levels and +.059 in growth rates. The correlations between the Conference Board index and the two expectations components are quite weak, a sharp contrast to the behavior of the broad Michigan index, which is strongly correlated with the two expectations components.

\section{Causality and Forecasting}

In recent years, consumer confidence has received considerable attention in the business and popular press as a coincident and leading indicator for consumption. As seen in Figure 1, a strong contemporaneous and leading relationship exists between the cyclical components of consumer confidence and consumption, and it is usually 
the case that the strongest correlation between consumer confidence and consumption is found when confidence is lagged one to four quarters. Further evidence is found by performing formal causality tests on sentiment and consumption growth rates. Reported in Table 1c, both Granger and Sims [1972] tests suggest that consumer confidence generally causes consumption at at least the $10 \%$ level. ${ }^{3}$ (Granger causality tests on the Conference Board indexes produce the only two outliers.) Although the established fact that these tests are sensitive to model specification makes these results inconclusive, they are nonetheless a good starting point for further investigation into the relationship between consumer confidence and household spending.

TABLE 1

\begin{tabular}{lcc}
\multicolumn{2}{c}{ Summary Statistics for Consumer Confidence Indexes } \\
\hline (a) Volatility & $\begin{array}{c}\text { St. Dev. } \\
\text { (Log Levels) }\end{array}$ & $\begin{array}{c}\text { St. Dev. } \\
\text { (Growth Rate) }\end{array}$ \\
\hline Conference Board & 0.3809 & 0.1670 \\
Conference Board Expectations & 0.0911 & 0.1146 \\
University of Michigan & 0.0640 & 0.0650 \\
University of Michigan Expectations & 0.0244 & 0.0386 \\
Consumption & 0.0075 & 0.0043 \\
Income & 0.0112 & 0.0082
\end{tabular}

\begin{tabular}{|c|c|c|c|}
\hline $\begin{array}{l}\text { (b) Correlations } \\
\text { Log Levels, (Growth Rates) }\end{array}$ & $\begin{array}{l}\text { Conference Board } \\
\text { Expectations }\end{array}$ & Michigan & $\begin{array}{c}\text { Michigan } \\
\text { Expectations }\end{array}$ \\
\hline Conference Board & $0.34,(0.44)$ & $0.61,(0.49)$ & $0.19,(0.18)$ \\
\hline Conference Board Expectations & & $0.81,(0.83)$ & $0.79,(0.59)$ \\
\hline University of Michigan & & & $0.74,(0.75)$ \\
\hline (c) Causality Tests & $\boldsymbol{F}$ & $p$-value & \\
\hline \multicolumn{4}{|l|}{ Granger } \\
\hline Conference Board & 1.9718 & 0.1081 & \\
\hline Conference Board Expectations & 1.2777 & 0.2865 & \\
\hline University of Michigan & 2.3822 & 0.0304 & \\
\hline \multicolumn{3}{|l|}{ Sims } & \\
\hline Conference Board & 3.1463 & 0.0134 & \\
\hline Conference Board Expectations & 2.3443 & 0.0509 & \\
\hline University of Michigan & 2.9061 & 0.0198 & \\
\hline University of Michigan Expectations & 2.7283 & 0.0271 & \\
\hline $\begin{array}{l}\text { Level standard deviations and c } \\
\text { filtered data }(\lambda=1600) \text {. }\end{array}$ & s in Tables (a) an & calculated & Hodrick-Prescott \\
\hline $\begin{array}{l}\text { 2) Lag length (Granger) }=4 \text {; lag/lea } \\
\text { sion of lags } 1-4 \text { of consumer confi } \\
\text { lags of the growth rate in consur } \\
\text { of consumption is a regression of } \\
\text { df }=4,71 \text { (Sims). }\end{array}$ & $\begin{array}{l}(\mathrm{Sims})=4 . \text { Figure rep } \\
\text { a regression of consur } \\
\text { idence, } \mathrm{df}=4,65 \text { (Gran } \\
\text { er confidence growth }\end{array}$ & $\begin{array}{l}\text { ted is the LN } \\
\text { tion growth } \\
\text { er) OR for th } \\
\text { lags }-4 \text { to } 4\end{array}$ & $\begin{array}{l}\text { astic for the exclu- } \\
\text { AR terms and four } \\
\text { lusion of leads 1-4 } \\
\text { sumption growth, }\end{array}$ \\
\hline
\end{tabular}

The evidence for the predictive power of consumer confidence in formal forecasting models is mixed, and depends largely on which measure of consumer confidence is employed. Most academic research on consumer confidence in the U.S. has focused on the Michigan index, a likely function of its longer history [Bram and Ludvigson, 1998]. ${ }^{4}$ This longer history, however, appears to come at a price of minimal, if any, forecasting efficacy. Madsen and McAleer [2000], for example, find that the Michigan 
index has no predictive power for consumer spending when used as an explanatory variable in a standard forecasting model of the form

$$
\Delta \log \left(c_{t}\right)=\alpha_{0}+\gamma Z_{t}+e_{t}
$$

where $c_{t}$ denotes date $t$ consumption spending, $\alpha_{0}$ a constant term, $Z_{t}$ a vector of controls (including lagged consumption and income growth) with coefficient vector $\gamma$, and $e_{t}$ is the error term. Contrary evidence is presented by Carroll et al. [1994] and Bram and Ludvigson, who, using similar models, suggest that the addition of the Michigan index results in a marginal increase in forecasting power-as measured by a slight increase in the associated regression's $R^{2}$ statistic-for consumption growth beyond that found in other relevant economic indicators.

FIGURE 1

${\text { Correlation: } \text { confidence }_{t+k} \text {, consumption }}_{t}$

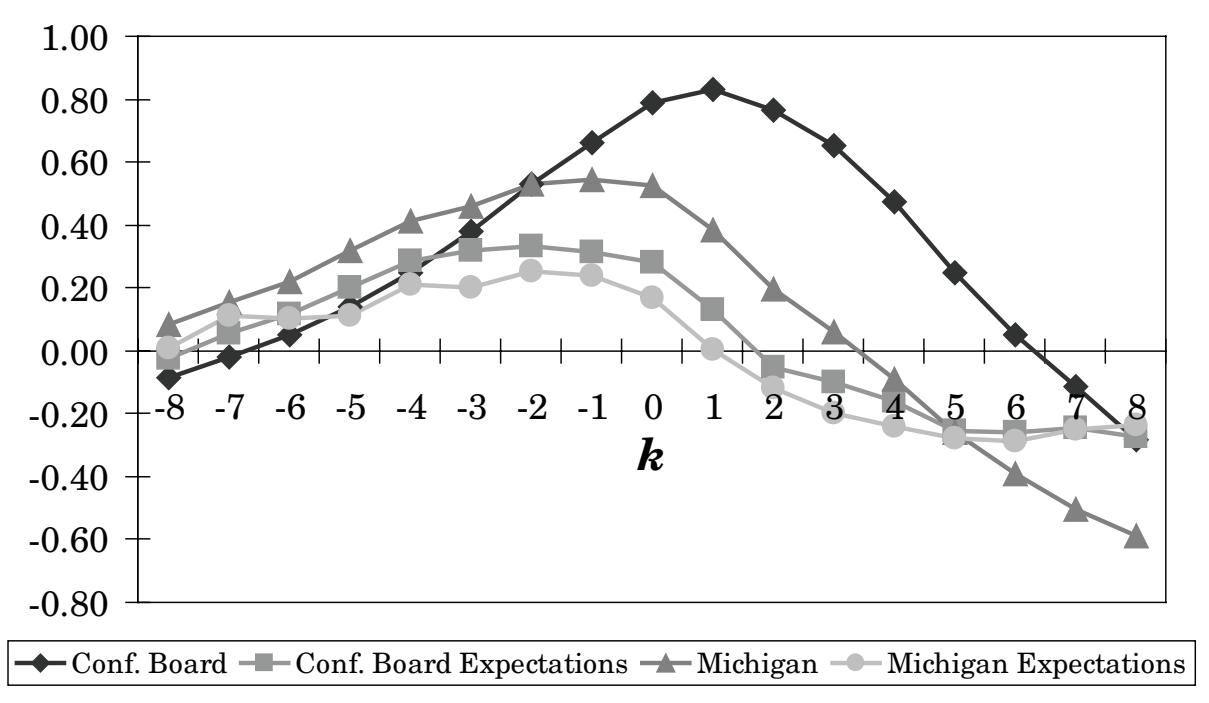

Note: 1) Moments calculated from HP filtered data.

Better and more consistent results are obtained with the Conference Board indexes. Namely, the inclusion of the Conference Board index in a forecasting model like the one above results in an approximate $10 \%$ increase in forecasting and explanatory power [Bram and Ludvigson]. One possible explanation for this is the fact that the Conference Board index is more timely; the Consumer Confidence Index is usually released about two weeks prior to its (final) Michigan counterpart. ${ }^{5}$ As such, the Conference Board index is more closely watched by financial markets and the business community, and is thus more likely to have a larger impact on economic activity. For this reason, the Conference Board index is used as the baseline confidence metric in this study. 


\section{THE PIH AND CONSUMER ATTITUDES}

Life-cycle/permanent income models of consumption suggest that consumption decisions are dynamic in nature, in particular that current consumption expenditures are proportional to lifetime or permanent income, $y_{t}^{P}$ :

$$
c_{t}=k y_{t}^{P} \text {. }
$$

$k$ is a constant in the $(0,1]$ interval. Although at its most elementary level the intuition underlying the PIH is very compelling, the fact that future income streams are uncertain makes empirically testable PIH models considerably more sophisticated than the simple formulation presented above. Indeed, most of the major contributions in the voluminous body of literature that followed the initial work in this area by Friedman [1957] and Modigliani and Brumberg [1954] are concerned with how to best deal with such uncertainty. ${ }^{6}$ Under rational expectations regarding future income-along with two other common PIH assumptions, perfect capital markets and certainty equivalence-the primary implication of the PIH is that changes in consumption spending are solely the result of changes in future income expectations (see Flavin [1981]). That is,

$$
\Delta c_{t}=r \sum_{t=0}^{\infty} \beta^{t}\left(E_{t}-E_{t-1}\right) y_{t},
$$

where $y_{t}$ is measured income at date $t, r$ the real interest rate, $\beta$ a subjective discount factor, and $E_{j}$ the expectations operator conditional on the date $j$ information set.

In this environment, consumer confidence as a coincident indicator is consistent with even the strictest versions of the PIH insofar it signals changes in individuals' expectations about future income. Additionally, consumer confidence is significantly influenced by current macroeconomic indicators such as interest rates, inflation, unemployment, stock market performance, and income growth. This is illustrated in Table 2, which reports the results of regressing the natural logarithm of the four measures of consumer confidence on these five variables. Not surprisingly, procyclical indicators significantly boost consumer confidence while countercyclical indicators significantly worsen it: regardless of how measured, consumer confidence usually depends positively on the interest rate, income growth, the return on the S\&P 500 index and negatively on the unemployment rate and inflation. The fact that many of these variables have some predictive power for future macroeconomic performance, and thus permanent income, reinforces consumer confidence's role as a coincident indicator in the context of the PIH.

As a leading indicator, however, consumer confidence runs afoul of the PIH. Under the PIH, changes in expectations regarding future income embodied in consumer confidence or any other salient indicator will be reflected in current spending plans; future innovations in consumption will occur only when future expectations of permanent income change. Thus, consumer confidence should have no predictive power for 
consumption if the PIH holds. This "excess sensitivity" of consumption with regard to consumer confidence and/or that consumer confidence Granger-causes consumption has been suggested as a reason to reject the PIH [Acemoglu and Scott, 1994; Matsusaka and Sbordone, 1995]. This is also the case even if one relaxes the perfect capital markets assumption [Zeldes, 1989]. ${ }^{7}$

TABLE 2

\begin{tabular}{|c|c|c|c|c|}
\hline & Determin & ts of Consumer & Confidence & \\
\hline Variable & $\begin{array}{l}\text { Conference } \\
\text { Board }\end{array}$ & $\begin{array}{c}\text { Conference Board } \\
\text { (expectations) }\end{array}$ & $\begin{array}{c}\text { University of } \\
\text { Michigan }\end{array}$ & $\begin{array}{c}\text { University of Michigan } \\
\text { (expectations) }\end{array}$ \\
\hline$\overline{\text { Constant }}$ & $2.325 * * *$ & $5.030^{* * * *}$ & $4.434^{* * *}$ & $4.904^{* * * *}$ \\
\hline & $(0.496)$ & $(1.041)$ & $(0.814)$ & $(0.031)$ \\
\hline Lagged confidence & $0.626 * * *$ & -0.105 & 0.060 & $0.792^{* * *}$ \\
\hline & $(0.073)$ & $(0.226)$ & $(0.171)$ & $(0.083)$ \\
\hline Current interest rate & $0.031 * *$ & $0.045^{* * *}$ & $0.016^{* * *}$ & 0.002 \\
\hline & $(0.013)$ & $(0.012)$ & 0.005 & $(0.003)$ \\
\hline Current inflation rate & $-0.024 * *$ & $-0.052^{* * *}$ & $-0.039 * * *$ & $-0.011 * *$ \\
\hline & $(0.011)$ & $(0.011)$ & $(0.005)$ & $(0.005)$ \\
\hline Current jobless rate & $-0.133 * * *$ & $-0.024 *$ & $-0.036 * * *$ & $-0.012^{* * *}$ \\
\hline & $(0.033)$ & $(0.014)$ & $(0.010)$ & $(0.004)$ \\
\hline Return on S\&P 500 & $0.004 * *$ & $0.003^{*}$ & $0.002 * *$ & $0.001^{* * *}$ \\
\hline & $(0.001)$ & $(0.001)$ & $(0.001)$ & $(0.0003)$ \\
\hline Year-ago income growth & $0.028 * * *$ & 0.016 & $0.018 * * *$ & $0.009 * * *$ \\
\hline & $(0.010)$ & $(0.010)$ & $(0.006)$ & $(0.002)$ \\
\hline $\mathrm{MA}(1)$ & $0.671 * * *$ & $0.678 * * *$ & $0.429 * * *$ & $0.724 * * *$ \\
\hline & $(0.094)$ & $(0.137)$ & $(0.136)$ & $(0.116)$ \\
\hline & 0.960 & 0.680 & 0.884 & 0.867 \\
\hline Durbin-Watson & 1.962 & 1.995 & 1.979 & 1.707 \\
\hline F-statistic & 274.622 & 20.002 & 87.224 & 74.780 \\
\hline
\end{tabular}

Notes:

1) Estimation method: OLS; Sample period 1979:Q1-1998:Q4.

2) Standard errors in parentheses.

3) $* * *=$ significant at $1 \%$ level; $* *=$ significant at $5 \%$ level; $*=$ significant at $10 \%$ level.

4) Dependent variable is confidence metric in logs.

5) Interest rate: 3-mo. t-bill; inflation: year-ago change in the CPI; income: real per-capita personal income.

There are, however, a variety of explanations for the predictive power of consumer confidence that can be consistent with appropriately-modified versions of the PIH. For example, consumer confidence may reflect some private information regarding permanent income prospects [Acemoglu and Scott]. A similar possibility is that this information is not private, but rather unobservable or unusable for empirical purposes. In addition, consumer sentiment may be a measure of uncertainty [Acemoglu and Scott] or it may be capturing systematic deviations from rational decision-making, e.g. "animal spirits." One or a combination of these factors could result in consumption spending growth out of line with a rational expectations forecast of permanent income. These factors could also result in precautionary saving, that is, a breakdown in certainty equivalence, and hence a rejection of the PIH as it will result in higherthan-expected consumption growth. Other explanations include Carroll et al.'s [1994] suggestion that consumer confidence may be an "independent driving factor in the economy" or a preference shock with a timing convention that results in some predic- 
tive power for consumer confidence. In short, to avoid a partial or outright rejection, the PIH must be modified to include consumer confidence.

\section{THE CONFIDENCE-AUGMENTED PIH}

Hall's [1978] "Euler equation approach" expresses the PIH as the intertemporal optimization problem facing a household that maximizes expected lifetime utility under uncertainty. A standard Euler equation-based life-cycle/permanent income model begins with a representative household that chooses a sequence of consumption, $\left\{c_{t}\right\}_{t=0}^{\infty}$, to maximize expected discounted lifetime utility, $U$ :

$$
U=E_{0} \sum_{t=0}^{\infty} \beta^{t} u\left(c_{t}\right),
$$

subject to the following budget constraint:

$$
y_{t}+\left(1+r_{t-1}\right) A_{t-1}=c_{t}+A_{t}
$$

All of the notation in the above expressions has been previously defined, with the exceptions of $A_{t}$, which is some as-yet unspecified real-valued asset valued at date $t$. Equivalently, $A_{t}$ could be interpreted as a vector of assets with associated interest rate vector $r_{t-1}$. The associated Euler equation is

$$
E_{t}\left[\left(u_{c_{t+1}} / u_{c_{t}}\right)-\beta\left(1+r_{t}\right)\right]=0
$$

where $u_{c_{j}}$ denotes the first derivative of the momentary utility function with respect to consumption at date $j$. This equation defines the PIH and, in various guises, has become the workhorse model of empirical consumption research based on the Euler equation approach [Attanasio, 1999]. If the momentary utility function assumes the typical CRRA form

$$
u\left(c_{t}\right)=[1 / 1-\sigma]\left(c_{t}\right)^{1-\sigma}-1
$$

equation (1) becomes

$$
E_{t}\left\{\left(c_{t+1} / c_{t}\right)-\left[\beta\left(1+r_{t}\right)\right]^{1 / \sigma}\right\}=0
$$

where $1 / \sigma$ is the intertemporal elasticity of substitution in consumption, a key parameter in asset pricing theory [Hansen and Singleton, 1983; Hall, 1988]. As such, a side issue of some interest will be to examine how the explicit presence of consumer confidence affects this parameter's value and robustness compared to prior studies. 
Consumer confidence, $\theta$, is introduced through the household utility function, entering as a "shift" term of sorts on preferences:

$$
u\left(c_{t}, \theta_{t-1}\right)=\theta_{t-1} u\left(c_{t}\right)
$$

Precedent for a demand shift term such as this is found in the quantitative general equilibrium literature, where similar constructs have been used to drive business cycle models or to augment an existing forcing process (see Baxter [1996] and Stockman and Tesar [1995] for more information).

A few words on the timing convention with regard to consumer confidence are in order. First, this scheme is attractive in that it directly captures the leading indicator aspect of consumer confidence. Moreover, it is also the case that consumer confidence is a function of the date $t$ state of nature; the current "stock" of consumer confidence is being built by current household spending and other fundamental conditions. Formally, the suggested timing convention is one where individuals enter a period with a certain (predetermined) level of confidence which affects that period's consumption decisions. This in turn influences the overall state of the economy and thus that period's level of confidence.

This augmentation changes the Euler equation as follows:

$$
E_{t}\left\{\left(c_{t+1} / c_{t}\right)-\left[\left(\theta_{t} / \theta_{t-1}\right) \beta\left(1+r_{t}\right)\right]^{1 / \sigma}\right\}=0
$$

This equation defines the "confidence-augmented" permanent income hypothesis (henceforth CAPIH).

\section{ESTIMATION PROCEDURE AND BASELINE RESULTS}

Following Campbell and Mankiw [1990], testing the CAPIH begins by first positing that some share (1- $\rho)$ of households are current income consumers. For them, consumption is related to current income via a standard Keynesian specification:

$$
E_{t}\left[\left(c_{t+1} / c_{t}\right)-\left(y_{t+1} / y_{t}\right)\right]=0
$$

For these households, consumption is a function of current income by definition; consumer confidence does not affect current income spending. Note that this specification is intuitively consistent with the dating convention employed in the CAPIH model. That is, since current income is a function of current consumer confidence, past values of consumer confidence should not affect the spending plans of current-income consumers. If the other share $\rho$ of the population are confidence-augmented permanent income consumers, the two consumption models can be nested as follows: 


$$
E_{t}\left\{\left(c_{t+1} / c_{t}\right)-\rho\left[\mu+\left(\left(\theta_{t} / \theta_{t-1}\right) \beta\left(1+r_{t}\right)\right)^{1 / \sigma}\right]-(1-\rho)\left(y_{t+1} / y_{t}\right)\right\}=0
$$

where $\mu$ is a drift term commonly included in empirical PIH models.

To estimate equation (5), define the stationary error function, $\varepsilon_{t+1}(\Psi)$ as follows:

$$
\varepsilon_{t+1}(\Psi)=\left(c_{t+1} / c_{t}\right)-\rho\left[\mu+\left(\left(\theta_{t} / \theta_{t-1}\right) \beta\left(1+r_{t}\right)\right)^{1 / \sigma}\right]-(1-\rho)\left(y_{t+1} / y_{t}\right)
$$

where the vector $\Psi=(\rho, \mu, 1 / \sigma)$. The subjective discount factor is preset to .9879; this corresponds to a steady state real interest rate of about 5\%. (Empirical results are largely invariant to any value of $\beta$ in the $[0.90,0.99]$ interval.) The associated orthogonality condition is

$$
E_{t}\left[\mathbf{W}_{t}^{\prime} \varepsilon_{t+1}(\Psi)\right]=0
$$

where $\mathbf{W}_{t}$ is a vector of instruments consisting of the date $t$ information set. $\Psi$ is then estimated using a nonlinear GMM-IV procedure. This protocol, direct estimation of the Euler equation-as opposed to first making some linear approximation-is attractive for two reasons: first, unlike the linearized models studied by Hansen and Singleton [1983], Hall [1978; 1988], and others, it does not require making an assumption concerning the joint distribution of consumption and asset returns and in this context, consumer confidence. Second, this method also avoids the potential for costly approximation errors [Wirjanto, 1996].

Permanent income models are commonly estimated with an overidentifying number of instruments. This, coupled with the fact that there is a potentially infinite number of permissible instrument sets, implies that the GMM-IV estimate of $\Psi$ will not be unique. While it is possible to construct efficiency bounds for the estimate of $\Psi$, it is out of the scope of this study to do so; I will instead echo precedent and report estimates obtained using a variety of reasonable instrument sets and test the validity of each moment condition using Hansen's [1982] $J$-test. Similar to those used by Campbell and Mankiw [1990] and Wirjanto [1996], these instrument sets are

$$
\begin{aligned}
& \mathbf{W}_{1}=\left\{1, y_{t} / y_{t-1}, y_{t-1} / y_{t-2}, y_{t-2} / y_{t-3}, r_{t-1} / r_{t-2}\right\} \\
& \mathbf{W}_{2}=\left\{1, c_{t} / c_{t-1}, c_{t-1} / c_{t-2}, c_{t-2} / c_{t-3}, y_{t} / y_{t-1}, y_{t-1} / y_{t-2}, y_{t-2} / y_{t-3}\right\}, \\
& \mathbf{W}_{3}=\left\{1, c_{t} / c_{t-1}, c_{t-1} / c_{t-2}, c_{t-2} / c_{t-3}, y_{t} / y_{t-1}, y_{t-1} / y_{t-2}, y_{t-2} / y_{t-3}, r_{t-1} / r_{t-2}\right\}, \\
& \mathbf{W}_{4}=\left\{1, c_{t} / c_{t-1}, c_{t-1} / c_{t-2}, c_{t-2} / c_{t-3}, y_{t} / y_{t-1}, y_{t-1} / y_{t-2}, y_{t-2} / y_{t-3}, r_{t-1} / r_{t-2}, c_{t-1} / y_{t-1}\right\} .
\end{aligned}
$$

The results of estimating equation (7) with each instrument set and for all four measures of consumer confidence are found in Tables 3 and 4. For brevity, I do not report 
the estimated value of the drift parameter, $\mu$, which was found to be small and statistically insignificant for all versions of the model. In addition to the usual regression results, I report the aforementioned $J$-test statistic and the Durbin-Watson statistic. The $J$-statistic forms the basis of a test for overidentification, and is calculated by multiplying the minimized value of the GMM objective function by the sample size. Under the null hypothesis of a correctly specified model, the $J$-statistic follows a $\chi^{2}$ distribution with degrees of freedom equal to the number of overidentifying restrictions, that is, the number of instruments less the number of estimated parameters; see the technical appendix for a description of this test. A significant $J$-test statistic is evidence of model mis-specification. The Durbin-Watson statistic is reported since the presence of serial correlation is grounds to reject the PIH and/or CAPIH as serially correlated errors contain information helpful in forecasting consumption.

For comparison purposes, results from estimating a confidence-free version of - that is, a "standard" nonlinear PIH model-are reported in the top panel of Table 3. The standard PIH model's estimates of $\rho$ (located in column two) are statistically significant at $1 \%$ for all four instrument sets, and place the share of permanent income households in the $60 \%$ range. These results are especially noteworthy in comparison to those of the Campbell and Mankiw study, which estimates the share of permanent income households to be around $30 \%$; the implications of a parameter shift of this magnitude for researchers and forecasters employing nested models of this type are obvious. As Campbell and Mankiw employ a linear regression model, approximation error may explain this seeming discrepancy, although an analogous result is suggested by Wirjanto, who fits a nonlinear model very similar to the one employed here to Canadian data.

Found in the third column, estimates of the intertemporal elasticity of substitution $(1 / \sigma)$ are statistically significant and fall in the $0.12-0.18$ range. This finding is largely consistent with the previously-cited studies using aggregate-level data insofar the intertemporal elasticity of substitution tends to be "small" [Campbell and Mankiw; Hall, 1988]. Finally, as observed in columns four and five respectively, the associated $J$-tests for each instrument set are insignificant, and there is little evidence of first-order serial correlation in the residuals as evidenced by all four Durbin-Watson statistics hovering in the neighborhood of two.

Regression results from the baseline CAPIH model (estimated using the Conference Board index) are found in the bottom panel of Table 3. With a +0.65 mean estimate of $\rho$, the CAPIH model predicts a slightly higher proportion of permanent income households, but this is not significantly different than the average share predicted by the standard PIH models. The same cannot be said of the intertemporal elasticity of substitution, as augmenting the PIH model with consumer confidence results in a tenfold decrease in the estimated intertemporal elasticity of substitution. This difference in $1 / \sigma$ across the PIH and CAPIH models is statistically significant, and potential explanations for this finding and possible implications will be discussed presently. As with the standard PIH model, the $J$-test uncovers virtually no evidence of model mis-specification and the Durbin-Watson statistics suggest little evidence of serial correlation. 
The performance of the CAPIH model is not radically altered by substituting the University of Michigan index. As noted in the top panel of Table 4, estimates of $\rho$ are significant at $5 \%$ or better for the Michigan index regardless of instrument set. Averaging greater than $0.75, \rho$ is noticeably higher when the model is estimated using the Michigan index, but this difference is not statistically significant from the baseline CAPIH results. Using the Michigan index approximately triples the estimated value of the intertemporal elasticity of substitution, but this increase is again not statistically significant. Finally, the $J$ - and Durbin-Watson statistics for each instrument set are still no cause for concern: the former are all small and insignificant, the latter are all close to two in magnitude.

TABLE 3

Baseline Results for Permanent Income Models

\begin{tabular}{lcccc} 
Standard PIH Model & & & \\
Instruments & $\rho$ & $1 / \sigma$ & J (df) & Durbin-Watson \\
\hline $\mathbf{W}_{\mathbf{1}}$ & $0.708^{* * *}$ & $0.153^{*}$ & $0.0021(2)$ & 1.834 \\
& $(0.275)$ & $(0.085)$ & & \\
$\mathbf{W}_{\mathbf{2}}$ & $0.615^{* * *}$ & $0.183^{* *}$ & $0.0036(4)$ & 1.963 \\
& $(0.148)$ & $(0.081)$ & & \\
$\mathbf{W}_{3}$ & $0.599^{* * *}$ & $0.176^{* *}$ & $0.0040(5)$ & 2.016 \\
& $(0.160)$ & $(0.079)$ & & 2.107
\end{tabular}

Confidence-augmented PIH Model

\begin{tabular}{lcccc} 
Instruments & $\rho$ & $\mathbf{1} / \sigma$ & $\mathbf{J}(\mathbf{d f})$ & Durbin-Watson \\
\hline $\mathbf{W}_{\mathbf{1}}$ & $0.747^{* * *}$ & $0.016^{*}$ & $0.0023(2)$ & 1.911 \\
& $(0.238)$ & $(0.008)$ & & 2.061 \\
$\mathbf{W}_{\mathbf{2}}$ & $0.619^{* * *}$ & $0.014^{* *}$ & $0.0055(4)$ & 2.012 \\
& $(0.159)$ & $(0.006)$ & & \\
$\mathbf{W}_{\mathbf{3}}$ & $0.654^{* * *}$ & $0.013^{* *}$ & $0.0063(5)$ & 2.001 \\
& $(0.144)$ & $(0.006)$ & & $0.0077(6)$ \\
$\mathbf{W}_{4}$ & $0.663^{* * *}$ & $0.013^{* *}$ & & \\
\hline
\end{tabular}

Notes:

1) Consumer Confidence: Conference Board Index of Consumer Confidence; Interest Rate: 3-mo. Commercial Paper.

2) Standard errors in parentheses.

3) $* * *=$ significant at $1 \%$ level; $* *=$ significant at $5 \%$ level; * = significant at $10 \%$ level.

4) The $5 \% \chi^{2}$ critical values for the J-test with $2,4,5$, and 6 df are 5.99, 9.49, 11.07, and 12.59, respectively.

The bottom two panels of Table 4 contain the results obtained by estimating the CAPIH using the expectations component of the Conference Board and Michigan indexes. Substituting the expectations component of each index results in generally subtle changes in results relative to those obtained using the broad indexes. For example, estimates of the share of permanent income households are slightly higher when utilizing the expectations component of the Conference Board series instead of the broad index, but this difference is not statistically significant. The University of Michigan expectations component usually yields smaller estimates of $\rho$ than the broad Michigan index, but this difference is likewise insignificant. 
The results regarding the intertemporal elasticity of substitution are slightly weaker when utilizing the Conference Board expectations series. While they do not appear different in magnitude from the results obtained with the broad Conference Board index, estimates of the intertemporal elasticity of substitution tend to be less significant: 1 / $\sigma$ is significant at $5 \%$ only when estimated with instrument set $\mathbf{W}_{4}$, at $10 \%$ when estimated using $\mathbf{W}_{2}$ and $\mathbf{W}_{3}$, and insignificant under $\mathbf{W}_{1}$. Differences in the magnitudes and patterns of significance for the estimates of $1 / \sigma$ are not noteworthy between the broad University of Michigan index and its expectations component. Finally, $J$-test results and Durbin-Watson statistics are uniformly favorable; as with the broad indexes, there are no apparent problems with mis-specification or serial correlation when the CAPIH model is estimated with either expectations component.

TABLE 4

CAPIH Results With Alternate Confidence Indexes

\begin{tabular}{lcccc}
$\begin{array}{l}\text { University of Michigan } \\
\text { Instruments }\end{array}$ & $\rho$ & $\mathbf{1} \sigma$ & $\mathbf{J}(\mathbf{d f})$ & Durbin-Watson \\
\hline $\mathbf{W}_{\mathbf{1}}$ & $0.699^{* * *}$ & 0.059 & $0.0058(2)$ & 2.228 \\
& $(0.317)$ & $(0.059)$ & & \\
$\mathbf{W}_{2}$ & $0.754^{* * * *}$ & $0.041^{* *}$ & $0.0038(4)$ & 2.081 \\
& $(0.200)$ & $(0.019)$ & & 2.055 \\
$\mathbf{W}_{3}$ & $0.797^{* * *}$ & $0.041^{* *}$ & $0.0042(5)$ & 1.988 \\
& $(0.171)$ & $(0.020)$ & & $0.0076(6)$ \\
$\mathbf{W}_{4}$ & $0.783^{* * *}$ & $0.034^{*}$ & &
\end{tabular}

Conference Board Expectations

\begin{tabular}{lcccc} 
Instruments & $\rho$ & $\mathbf{1} / \sigma$ & $\mathbf{J}(\mathbf{d f})$ & Durbin-Watson \\
\hline $\mathbf{W}_{\mathbf{1}}$ & $0.632^{* * * *}$ & 0.009 & $0.0120(2)$ & 1.983 \\
& $(0.122)$ & $(0.020)$ & & 2.054 \\
$\mathbf{W}_{\mathbf{2}}$ & $0.670^{* * *}$ & $0.022^{*}$ & $0.0064(4)$ & 2.002 \\
& $(0.126)$ & $(0.013)$ & & $0.0074(5)$ \\
$\mathbf{W}_{3}$ & $0.693^{* * *}$ & $0.021^{*}$ & & \\
& $(0.121)$ & $(0.012)$ & $0.0101(6)$ & 1.985
\end{tabular}

University of Michigan Expectations

\begin{tabular}{lcccc} 
Instruments & $\rho$ & $\mathbf{1} / \sigma$ & $\mathbf{J}(\mathbf{d f})$ & Durbin-Watson \\
\hline $\mathbf{W}_{\mathbf{1}}$ & $0.879^{* * * *}$ & $0.068^{* * *}$ & $0.0047(2)$ & 1.911 \\
& $(0.140)$ & $(0.019)$ & & 2.017 \\
$\mathbf{W}_{\mathbf{2}}$ & $0.651^{* * *}$ & $0.051^{*}$ & $0.0094(4)$ & \\
& $(0.111)$ & $(0.027)$ & & \\
$\mathbf{W}_{3}$ & $0.671^{* * *}$ & $0.052^{* *}$ & $0.0102(5)$ & 2.995 \\
& $(0.106)$ & $(0.023)$ & $0.0136(6)$ & 2.005 \\
$\mathbf{W}_{\mathbf{4}}$ & $0.634^{* * *}$ & 0.035 & & \\
\end{tabular}

Notes:

1) Interest Rate: 3-mo. Commercial Paper.

2) Standard errors in parentheses.

3) $* * *=$ significant at $1 \%$ level; $* *=$ significant at $5 \%$ level; $*=$ significant at $10 \%$ level.

4) The $5 \% \chi^{2}$ critical values for the J-test with $2,4,5$, and 6 df are 5.99, 9.49, 11.07, and 12.59, respectively. 


\section{ALTERNATE ASSET RETURNS}

A natural investigation of the CAPIH framework is to explore its robustness to different asset returns. To this end, three alternate asset returns are considered: the 3 -month t-bill rate, equity returns as measured by the year-ago return on the S\&P 500 index, and an "effective" real household interest rate, $\widetilde{r}_{t}$. This yield is constructed by first stating that the household chooses its portfolio from a set of $n$ types of assets, each with associated real return $r_{t}^{i}$. Each asset is weighted by is respective portfolio share, $\omega^{i}$, where $\sum_{i=1}^{n} \omega^{i}=1 . \widetilde{r}_{t}$ is thus defined as follows:

$$
\tilde{r}_{t}=\sum_{i=1}^{n} \omega_{t}^{i} r_{t}^{i}
$$

For the practical purpose of constructing $\widetilde{r}_{t}$, I assume the universe of household assets consists of domestic equities, government bonds, corporate debt, bank deposits (CDs), and tangible assets, that is, real estate. The returns to these assets are described in the section "The PIH And Consumer Attitudes." While an admittedly simplistic approach, it is the case that these five broad asset categories comprise a dominant share of the average U.S. household portfolio. The weights are using the Federal Reserve's Flow of Funds data on household asset holdings. This data exists only at annual frequencies and as such, the weights are naively interpolated. ${ }^{8}$

TABLE 5a

\section{CAPIH Results With Alternate Interest Rates}

(3-month $t$-bill)

\section{Standard PIH Model}

Instruments

$\mathbf{W}_{1}$

$\rho 2 \quad \mathbf{1 / \sigma}$

$1 / \sigma$

J (df)

Durbin-Watson

$\mathbf{W}_{2}$

$(0.246) \quad(0.068)$

0.632 *** $\quad 0.164$ *

$0.0086(4)$

(1)

$\mathbf{W}_{3}$

$(0.138)$

(0.067)

$0.668^{* * * *}$

$0.158 * * *$

$0.0046(5)$

(1)

(0.159)

$\mathbf{W}_{4}$

$0.672 * * *$

(0.062)

$0.158 * * *$

$0.0121(6)$

1.950

(0.062)

Confidence-augmented PIH

\begin{tabular}{lcccc} 
Instruments & $\rho$ & $\mathbf{1} / \sigma$ & $\mathbf{J}(\mathbf{d f})$ & Durbin-Watson \\
\hline $\mathbf{W}_{\mathbf{1}}$ & $0.702^{* * * *}$ & $0.017^{* *}$ & $0.0022(2)$ & 1.950 \\
& $(0.234)$ & $(0.009)$ & & 2.060 \\
$\mathbf{W}_{\mathbf{2}}$ & $0.621^{* * *}$ & $0.014^{* *}$ & $0.0055(4)$ & 1.998 \\
& $(0.158)$ & $(0.006)$ & & \\
$\mathbf{W}_{\mathbf{3}}$ & $0.666^{* * *}$ & $0.013^{* *}$ & $0.0064(5)$ & 1.984 \\
$\mathbf{W}_{\mathbf{4}}$ & $(0.156)$ & $(0.006)$ & $0.0078(6)$ & \\
& $0.677^{* * *}$ & $0.013^{* *}$ & & \\
\hline
\end{tabular}

Notes:

1) Consumer Confidence: Conference Board Index of Consumer Confidence.

2) Standard errors in parentheses.

3) $* * *=$ significant at $1 \%$ level; $* *=$ significant at $5 \%$ level; * = significant at $10 \%$ level.

4) The $5 \% \chi^{2}$ critical values for the J-test with $2,4,5$, and $6 \mathrm{df}$ are 5.99, 9.49, 11.07, and 12.59, respectively. 
Tables 5a-5c summarize these results. Again, the results from a standard, that is, non-confidence augmented PIH model are included for comparison purposes. For each alternate asset return, issues of model specification and serial correlation are of no concern, as again evidenced by the very small $J$-test and near-two Durbin-Watson statistics reported in the fourth and fifth columns of each table, respectively. Substituting the treasury rate (Table 5a) has virtually no change in coefficient magnitudes for both models compared to the respective benchmarks; $\rho$ is again in the neighborhood of 0.60 under the PIH and is approximately 0.65 under the CAPIH. Similar results are seen for estimated intertemporal elasticity of substitution although the associated standard errors are slightly smaller.

TABLE 5b

CAPIH Results With Alternate Interest Rates

(Year-ago real return on S\&P 500)

\begin{tabular}{lcccc} 
Standard PIH Model & & & \\
Instruments & $\rho$ & $\mathbf{1} / \sigma$ & $\mathbf{J}(\mathbf{d f})$ & Durbin-Watson \\
\hline $\mathbf{W}_{\mathbf{1}}$ & $0.672^{* * *}$ & 0.012 & $0.0105(2)$ & 1.911 \\
& $(0.193)$ & $(0.015)$ & & \\
$\mathbf{W}_{\mathbf{2}}$ & $0.609 * * *$ & 0.014 & $0.0110(4)$ & 1.985 \\
& $(0.186)$ & $(0.014)$ & & 2.060 \\
$\mathbf{W}_{3}$ & $0.570^{* * *}$ & 0.011 & $0.0117(5)$ & 2.047 \\
$\mathbf{W}_{4}$ & $(0.172)$ & $(0.014)$ & & $0.0186(6)$ \\
& $0.588^{* * *}$ & $0.015^{* *}$ & &
\end{tabular}

Confidence-augmented PIH

\begin{tabular}{lcccc} 
Instruments & $\rho$ & $\mathbf{1} / \sigma$ & $\mathbf{J}(\mathbf{d f})$ & Durbin-Watson \\
\hline $\mathbf{W}_{\mathbf{1}}$ & $0.702^{* * *}$ & $0.017^{* * *}$ & $0.0045(2)$ & 1.907 \\
& $(0.234)$ & $(0.009)$ & & \\
$\mathbf{W}_{\mathbf{2}}$ & $0.621^{* * *}$ & $0.014^{* * *}$ & $0.0071(4)$ & 2.024 \\
& $(0.158)$ & $(0.006)$ & & \\
$\mathbf{W}_{3}$ & $0.666^{* * *}$ & $0.013^{* *}$ & $0.0080(5)$ & 2.047 \\
& $(0.156)$ & $(0.006)$ & & \\
$\mathbf{W}_{4}$ & $0.677^{* * *}$ & $0.013^{* *}$ & $0.0087(6)$ & 2.017 \\
& $(0.155)$ & $(0.006)$ & & \\
\hline
\end{tabular}

Notes:

1) Consumer Confidence: Conference Board Index of Consumer Confidence.

2) Standard errors in parentheses.

3) $* * *=$ significant at $1 \%$ level; $* *=$ significant at $5 \%$ level; $*=$ significant at $10 \%$ level.

4) The $5 \% \chi^{2}$ critical values for the J-test with $2,4,5$, and 6 df are 5.99, 9.49, 11.07, and 12.59, respectively.

As noted in Table 5b, more substantive changes are seen when the real return on equity is the asset return of choice. While using this rate does not significantly affect the estimated share of permanent income consumers in both models, estimating the standard PIH model with a stock market return has a dramatic impact on the intertemporal elasticity of substitution. In particular, $1 / \sigma$ is now in the $0.010-0.015$ range, a tenfold decrease from the baseline results. This results mirrors Hall [1988], who reports a fivefold decrease in the intertemporal elasticity of substitution when estimating a linearized PIH model with a dividend yield. Moreover, all PIH estimates of $1 / \sigma$ are insignificant with the exception of the model estimated with instrument set $\mathbf{W}_{4}$. 
In contrast, the CAPIH model delivers more stable estimates of the intertemporal elasticity of substitution: estimates of $1 / \sigma$ are essentially unchanged relative to baseline results under the CAPIH in both size and significance level. To understand this unexpected, but welcome result, recall that the return on equity is one of the fundamental determinants of consumer confidence (see Table 2). Thus, a "stock market effect" of sorts is already present in the empirical CAPIH model, regardless of what asset return it is estimated with. This also explains why $\rho$ does not change when using an equity yield in the CAPIH model.

Estimating the permanent income models using the effective household interest rate produces results similar to those obtained using the equity return. As seen in Table 5c, the estimated share of permanent income households is not statistically different from the baseline estimates. Estimates of $1 / \sigma$ under the CAPIH are unchanged from the baseline. Since equities account for an increasing share of household wealth, the estimated intertemporal elasticity of substitution for the standard PIH model is again significantly below the baseline. On the upside, the estimated values of $1 / \sigma$ are statistically significant for three of the four instrument sets in the standard PIH model. Lastly, given that housing is the other dominant asset the average or median household owns, this result provides evidence for the notion that households consider both financial and tangible asset returns when formulating consumption plans, as opposed to just financial ones.

TABLE 5c

CAPIH Results With Alternate Interest Rates

("Effective" household interest rate)

\begin{tabular}{lcccc} 
Standard PIH Model & & & \\
Instruments & $\rho$ & $\mathbf{1} \sigma$ & $\mathbf{J}(\mathbf{d f})$ & Durbin-Watson \\
\hline $\mathbf{W}_{\mathbf{1}}$ & $0.912^{* * * *}$ & 0.026 & $0.0091(2)$ & 1.537 \\
& $(0.231)$ & $(0.025)$ & & \\
$\mathbf{W}_{\mathbf{2}}$ & $0.707^{* * *}$ & $0.069^{* * * *}$ & $0.0076(4)$ & 1.947 \\
& $(0.164)$ & $(0.026)$ & & \\
$\mathbf{W}_{\mathbf{3}}$ & $0.606^{* * *}$ & $0.037^{* *}$ & $0.0112(5)$ & 2.141 \\
& $(0.160)$ & $(0.028)$ & & \\
$\mathbf{W}_{\mathbf{4}}$ & $0.647^{* * *}$ & $0.048^{* *}$ & $0.0176(6)$ & 2.071
\end{tabular}

Confidence-augmented PIH

\begin{tabular}{lcccc} 
Instruments & $\rho$ & $\mathbf{1} / \sigma$ & $\mathbf{J}(\mathbf{d f})$ & Durbin-Watson \\
\hline $\mathbf{W}_{\mathbf{1}}$ & $0.880^{* * *}$ & $0.011^{* *}$ & $0.0041(2)$ & 1.807 \\
& $(0.292)$ & $(0.005)$ & & \\
$\mathbf{W}_{\mathbf{2}}$ & $0.634^{* * *}$ & $0.012^{* *}$ & $0.0059(4)$ & 2.061 \\
& $(0.160)$ & $(0.005)$ & & 2.071 \\
$\mathbf{W}_{\mathbf{3}}$ & $0.628^{* * *}$ & $0.012^{* *}$ & $0.0071(5)$ & 2.021 \\
$\mathbf{W}_{4}$ & $(0.159)$ & $(0.005)$ & & \\
\end{tabular}

Notes:

1) Consumer Confidence: Conference Board Index of Consumer Confidence.

2) Standard errors in parentheses.

3) $* * *=$ significant at $1 \%$ level; $* *=$ significant at $5 \%$ level; $*$ = significant at $10 \%$ level.

4) The $5 \% \chi^{2}$ critical values for the J-test with $2,4,5$, and $6 \mathrm{df}$ are 5.99, 9.49, 11.07, and 12.59, respectively. 


\section{CONCLUSION}

The predictive power of consumer confidence questions the validity of life-cycle/ permanent income models of consumption. As a leading indicator, however, consumer confidence need not be inconsistent with the PIH, at least not in spirit; this paper shows this by developing a variant of the PIH that casts consumer confidence as a semi-stochastic shift term to preferences. By direct estimation of the Euler equation, this "confidence-augmented" PIH model was tested against a current income consumption specification and compared to a traditional PIH setup.

In contrast to prior studies using U.S. or Canadian data, the predicted share of permanent income households is fairly large under both the (nonlinear) PIH and CA$\mathrm{PIH}$, in the 60-65\% ballpark. Previous research, which typically employs linear models, estimates this parameter to be approximately $30 \%$. In addition to suggesting a much higher incidence of permanent income consumption than previously thought-and thus greater support for life-cycle/permanent income theories of consumption in general-a parameter shift of this size is strong evidence supporting the use of nonlinear consumption models in empirical consumption analysis and forecasting.

In addition, the CAPIH predicts a slightly higher share of permanent income consumers than a non-confidence augmented model. Empirically, this is attributable to the strong contemporaneous correlation between consumer confidence and income; theoretically, explicitly including consumer confidence is acting to decrease the household's rate of time preference. These differences are statistically insignificant, regardless. The CAPIH model also suggests that the intertemporal elasticity of substitution is significantly smaller in magnitude compared to what is predicted by a standard PIH model and what is reported in prior studies. More importantly, the CAPIH estimates of the intertemporal elasticity of substitution are robust with respect to the choice of instruments and asset returns, a result not observed with standard PIH models.

The predictive power of consumer confidence and the theoretical elegance of the life-cycle/permanent income theory of consumption need not be mutually exclusive concepts. For this to be the case, however, consumer confidence must be explicitly incorporated in model building, estimation, and forecasting. The good news is that this can be done fairly simply, even in a nonlinear environment. Indeed, the cost in terms of added complexity of modifying empirical Euler equation-based consumption models to incorporate some measure of consumer confidence is quite small relative to the associated benefits in terms of forecasting power and robustness of parameter estimates.

\section{NOTES}

I would like to thank Dick Claycombe, Brian Nottage, and two anonymous referees for suggestions and advice. All errors are mine.

1. See Bram and Ludvigson [1998] for a thorough discussion of the methodological differences between the two indexes.

2. These results mirror those of Bram and Ludvigson, who note that "a one-point move in Michigan's index is roughly comparable to a two-point move in the Conference Board's index." 
3. Acemoglu and Scott [1994] find similar results using U.K. data.

4. The University of Michigan index was first calculated as an annual series in 1940. It was converted to a quarterly series 1952 and to a monthly one in 1978. The Conference Board index was first calculated in 1967 on a bimonthly basis with the switch to a monthly frequency occurring in 1977.

5. A preliminary number for the Michigan index is available prior to the release of the Conference Board index, but is constructed from a much smaller sample size which can result in large "white noise" fluctuations.

6. See Attanasio [1999] for a thorough survey of the life-cycle/permanent income literature.

7. If capital markets are imperfect, individuals may not be able to borrow against higher future income, which results in a rejection of the PIH.

8. These asset shares evolve very smoothly over time, so naive interpolation from annual to quarterly frequencies is not empirically egregious.

\section{TECHNICAL APPENDIX GMM ESTIMATION AND THE J-TEST}

Define $g_{t}(\Psi)=\mathbf{W}_{t}^{\prime} \varepsilon_{t+1}(\Psi)$, where as in the section on Estimation Procedure and Baseline Results, $\varepsilon$ denotes the stationary error function of dimension $s$ and $\mathbf{W}$ is a ( $q \times k$ ) matrix of instrumental variables. The optimal GMM estimate of $\Psi, \hat{\Psi}$, minimizes the criterion function:

$$
K(\Psi)=\left[(1 / T) \sum_{t=1}^{T} g_{t}(\Psi)\right]^{\prime} \hat{\mathbf{M}}\left[(1 / T) \sum_{t=1}^{T} g_{t} \Psi\right],
$$

where $T$ is the sample size and $\hat{\mathbf{M}}$ is a weighting matrix. $\hat{\Psi}$ will be an optimal and consistent estimator as long as $\hat{\mathbf{M}}$ is symmetric and positive semi-definite. $\hat{\mathbf{M}}$ is estimated using the common Newey-West [1987] paradigm. The $q$-s overidentifying restrictions are tested using Hansen's [1982] $J$-test. The test statistic $J$ is formed by multiplying the minimzed value of the criterion function, $K(\hat{\Psi})$, by the sample size. Under the null hypothesis of no mis-specification, $J$ follows a $\chi^{2}$ distribution with $q-s$ degrees of freedom. That is,

$$
J=T \cdot K(\hat{\Psi}) \sim \chi_{q-s}^{2}
$$

\section{REFERENCES}

Acemoglu, D. and Scott, A. Consumer Confidence and Rational Expectations: Are Agents Beliefs Consistent With the Theory? Economic Journal, January 1994, 1-19.

Abderrezak, A. Consumer Expectations and Cyclical Durations. Quarterly Review of Economics and Finance, Fall 1997, 843-857.

Attanasio, O. Consumption, in The Handbook of Macroeconomics, Volume 1B, edited by J. Taylor and M. Woodford. Amsterdam: Elsevier Science, 1999, 741-812.

Baxter, M. Are Consumer Durables Important For Business Cycles? Review of Economics and Statistics, February 1996, 147-155.

Bram, J. and Ludvigson, S. Does Consumer Confidence Forecast Household Expenditure? A Sentiment Index Horse Race. Federal Reserve Bank of New York Economic Policy Review, June 1998, 59-78. 
Campbell, J. and Mankiw, G. Permanent Income, Current Income, and Consumption. Journal of Business and Economic Statistics, July 1990, 265-279.

Carroll, C., Fuhrer, J., and Wilcox, D. Does Consumer Sentiment Forecast Household Spending? If So, Why? American Economic Review, December 1994, 1397-1408.

Danthine, J., Donaldson, J., and Johnsen, T. Productivity Growth, Consumer Confidence, and the Business Cycle. European Economic Review, June 1998, 1113-1140.

Flavin, M. The Adjustment of Consumption of Changing Expectations About Future Income. Journal of Political Economy, October 1981, 974-1009.

Friedman, M. A Theory of the Consumption Function. Princeton: Princeton University Press, 1957.

Hall, R. Stochastic Implications of the Life Cycle-Permanent Income Hypothesis: Theory and Evidence. Journal of Political Economy, December 1978, 971-987. 357.

Intertemporal Substitution in Consumption. Journal of Political Economy, April 1988, 339-

Hansen, L. Large Sample Properties of Generalized Method of Moments Estimators. Econometrica, July 1982, 1029-1054.

and Singleton, P. Stochastic Consumption, Risk Aversion, and the Temporal Behavior of Asset Returns. Journal of Political Economy, April 1983, 249-265.

Madsen, J. and McAleer, M. Direct Tests of the Permanent Income Hypothesis Under Uncertainty, Inflationary Expectations, and Liquidity Constraints. Journal of Macroeconomics, Spring 2000, 229-252.

Matsusaka, J. and Sbordone, A. Consumer Confidence and Economic Fluctuations. Economic Inquiry, April 1995, 296-318.

Modigliani, F. and Brumberg, R. Utility Analysis and the Consumption Function: An Interpretation of Cross-Section Data. Post-Keynesian Economics, edited by K. Kurihara. New Brunswick, NJ: Rutgers University Press, 1954.

Newey, W. and West, K. A Simple Positive Semi-Definite, Heteroskedasticity and Autocorrelation Consistent Covariance Matrix. Econometrica, May 1987, 703-708.

Sims, C. Money, Income, and Causality. American Economic Review, September 1972, 540-552.

Stockman, A. and Tesar, L. Tastes and Technology in a Two-Country Model of the Business Cycle: Explaining International Comovements. American Economic Review, March 1995, 168-185.

Wirjanto, T. An Empirical Investigation into the Permanent Income Hypothesis: Further Evidence from Canadian Data. Applied Economics, November 1996, 1451-1461.

Zeldes, S. Consumption and Liquidity Constraints: an Empirical Investigation. Journal of Political Economy, April 1989, 305-346. 